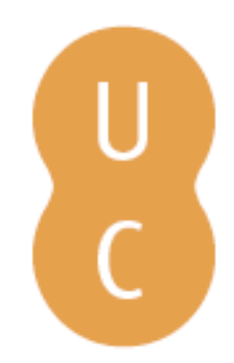

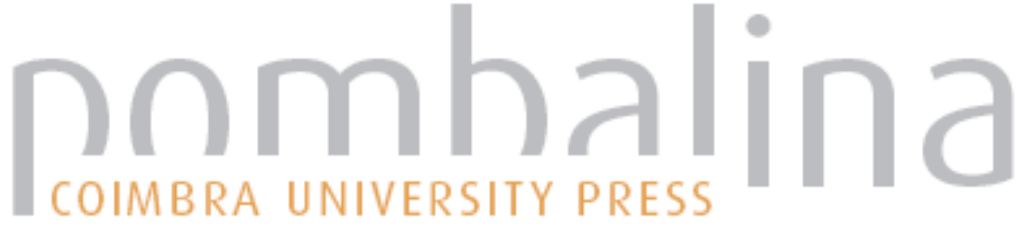

\section{O despertar do "país sonolento": contributo das feiras de produtos locais para um} novo projecto de desenvolvimento territorial

\author{
Autor(es): $\quad$ Azevedo, Nuno \\ Publicado por: Imprensa da Universidade de Coimbra \\ URL \\ persistente: URI:http://hdl.handle.net/10316.2/30766 \\ DOI: $\quad$ DOI:http://dx.doi.org/10.14195/978-989-26-0244-8_13 \\ Accessed : $\quad$ 26-Apr-2023 07:00:01
}

A navegação consulta e descarregamento dos títulos inseridos nas Bibliotecas Digitais UC Digitalis, UC Pombalina e UC Impactum, pressupõem a aceitação plena e sem reservas dos Termos e Condições de Uso destas Bibliotecas Digitais, disponíveis em https://digitalis.uc.pt/pt-pt/termos.

Conforme exposto nos referidos Termos e Condições de Uso, o descarregamento de títulos de acesso restrito requer uma licença válida de autorização devendo o utilizador aceder ao(s) documento(s) a partir de um endereço de IP da instituição detentora da supramencionada licença.

Ao utilizador é apenas permitido o descarregamento para uso pessoal, pelo que o emprego do(s) título(s) descarregado(s) para outro fim, designadamente comercial, carece de autorização do respetivo autor ou editor da obra.

Na medida em que todas as obras da UC Digitalis se encontram protegidas pelo Código do Direito de Autor e Direitos Conexos e demais legislação aplicável, toda a cópia, parcial ou total, deste documento, nos casos em que é legalmente admitida, deverá conter ou fazer-se acompanhar por este aviso.

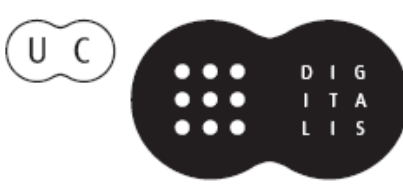




\section{TRUNFOS DE UMA}

\section{EOGRAFIA ACIVA}

\section{DESENVOLVIMENTO LOCAL,}

AMBIENTE,

ORDENAMENTO

E TECNOLOGIA

Norberto Santos

Lúcio Cunha

COORDENAÇÃO 
Nuno Azevedo

CEGOT. Bolseiro de Doutoramento da FCT (SFRH/BD/27717/2006).

\section{O DESPERTAR DO “PAÍS SONOLENTO": CONTRIBUTO DAS FEIRAS DE PRODUTOS LOCAIS PARA UM NOVO PROJECTO DE DESENVOLVIMENTO TERRITORIAL}

\section{UM PAÍS SONOLENTO EM PROCESSO DE MUDANÇA}

As importantes transformaçóes ocorridas no território nacional na segunda metade do século XX, e em particular no mundo rural do interior, foram tão intensas que se questionou a continuidade/desaparecimento do mundo rural (FIGUEIREDO, 1994). Porém, no final do séc. XX confirmou-se uma maior complexidade através de um país moderno e organizado mediante uma rede urbana, onde se afiguram pequenas e médias aglomeraçóes por todo o País, ao lado da faixa urbana litoral e das áreas metropolitanas, sendo as imagens da dicotomia litoral/interior e oposição cidade/campo simplistas, não sendo uniforme a diversidade sociodemográfica, com contextos socioterritoriais diversificados, construindo-se um território diferenciado e socialmente mais heterogéneo (MARQUES, 2004). Tal complexidade levou FERRÃO (2003) a distinguir «o país sob alta pressão», "o país tranquilo» e "o país sonolento». O «país sonolento» coincide com o interior predominantemente rural, que se encontra num círculo vicioso de subdesenvolvimento difícil de romper: repulsão demográfica, despovoamento, envelhecimento, estabilização ou mesmo degradação do capital humano. $\mathrm{O}$ autor recomenda que se deve evitar a leitura dicotómica de oposição entre o litoral moderno e desenvolvido e o interior tradicional e subdesenvolvido, sendo a realidade bem mais complexa.

Nos territórios de baixa densidade, vistos como regressivos, sonolentos e repulsivos, tem-se vindo a dinamizar processos de mudança, levando a crer que os territórios estão a acordar ou pelo menos a despertar. De facto, as transformaçóes recentes nestas regióes levou a que a conquista do espaço rural para utilizaçóes urbanas suscitasse um maior dinamismo e procura destes territórios (BAPTISTA, 2009). As mudanças têm provocado a diversificação dos espaços rurais, com a assunção do espaço multifuncional do campo (CAVACO, 2009). A aposta no turismo aliado à valorização da qualidade local é um caminho a seguir para a valorização. CRISTÓVÃO (1998) refere que é essencial atender ao público interessado, com oferta adequada às suas preferências, desenvolvendo a função residencial de fim-de-semana e férias, oferecendo produtos de qualidade, com originalidade e especificidade.

De facto, «o campo corporiza, actualmente, uma boa parte dos míticos lugares de (re)encontro, sendo procurado pela busca de identidade e de reconciliação, até mesmo 
descoberta, pela sua diversidade territorial e estética que se consubstancia e faz sentido enquanto natureza transformada, repositório de um vasto património material e imaterial legado por sucessivas civilizaçóes e modos de vida» (MARQUES, 2008: 1). Entre as alterações mais visíveis, as feiras de produtos locais estão a contribuir para a criação de uma nova inteligência colectiva, divulgando produçóes, costumes e dialectos, originando o despertar dos territórios e das identidades (re)descobertas e requalificadas. Funcionando como manifestação da cultura popular, de promoçáo e divulgação do artesanato, gastronomia, folclore e produtos locais de qualidade, redescobre-se e reconstroem-se os recursos locais, através da mobilizaçáo colectiva. São de certa forma uma montra dos municípios e da regiáo, procurando a valorizaçáo dos lugares, das gentes e das produçóes, criando novos alicerces para um novo projecto de desenvolvimento territorial.

Com as feiras locais revaloriza-se o rural (enquanto memória, património e paisagem), através de uma alavancagem a partir das autarquias. Neste âmbito, é necessário aproveitar os recursos do território, apostar na identidade local e na identificaçáo do consumidor com o lugar (os visitantes procuram uma imagem, uma representação rural, não significando que não estejam a ser reconstruídas as imagens e representaçóes). Assim, a identidade tem-se tornado um pilar da (re)afirmação de certas regióes, retomando-se e valorizando-se as tradiçóes económicas e culturais, recorrendo a estes eventos temáticos como âncoras de desenvolvimento.

\section{FEIRAS DE PRODUTOS LOCAIS EM TRÁS-OS-MONTES E ALTO DOURO}

Trás-os-Montes caracteriza-se pela ruralidade, tradicionalismo dos campos, pelas montanhas, pela gastronomia regional e artesanato. As feiras realizam-se durante todo o ano, reflexo das actividades agrárias, sendo eventos de cariz económico e lúdico que traduzem o ritmo da natureza e de outras celebraçóes, promovendo momentos de encontro e visitação em torno do mercado de produtos de qualidade que, na maioria dos casos, dão o nome às feiras temáticas. Através do levantamento efectuado junto das câmaras municipais é possível verificar a importância atribuída pelos municípios a estes eventos. Nos 34 concelhos realizam-se, pelo menos, 66 feiras anuais (Quadro 1), média de cerca de 2 feiras por município, existindo um evento em todos os municípios: vinho, no Douro Vinhateiro; amendoeira em flor no Douro Superior; fumeiro, na Terra Fria e Alto Tâmega; castanha na Terra Fria, Alto Tâmega e Douro Sul; maçá e cereja no Douro Sul e Terra Quente; oliveira e azeite na Terra Quente; artesanato, caça, turismo, cabrito e vitela um pouco por toda a região. Salienta-se a existência de eventos todo o ano, embora mais concentrados no $1^{\circ}, 2^{\circ} \mathrm{e}$ $3^{\circ}$ trimestres (17 a 19 eventos) que no $4^{\circ}$ (11). Apenas Valpaços realiza feiras em todos os trimestres, Miranda do Douro e Torre de Moncorvo têm eventos em 3 trimestres. Em 17 municípios estão concentrados em 1 trimestre e em 14 municípios em 2 trimestres.

Uma das consideraçôes prende-se com a atenção dada pelos «media» a estas iniciativas, os quais assumem um papel preponderante na divulgaçáo, fundamental para o sucesso e rentabilização: pense-se em quantos turistas ou investidores atraem as vulgares feiras semanais/mensais, em comparação com os cerca de 70.000 visitantes da Feira do Folar de Valpaços ou dos 80.000 visitantes da Feira do Fumeiro de Vinhais. 
Quadro 1-Feiras realizadas por município

\begin{tabular}{|c|c|}
\hline Município & Feiras realizadas \\
\hline Alfândega da Fé & Feira da Cereja e dos Produtos Locais/Biológicos \\
\hline Alijó & REVIDOURO; Feira dos Vinhos e Sabores do Pinhão \\
\hline Armamar & Feira das Actividades Económicas \\
\hline Boticas & Feira do Porco; Feira do Mel de Barroso e da Carne Barrosã \\
\hline Bragança & $\begin{array}{l}\text { Feira das Cantarinhas e Artesanato; Feira de Artesanato e Produtos } \\
\text { Regionais de Parada; Feira do Folar de Izeda. }\end{array}$ \\
\hline C. de Ansiães & Feira da Maçã, do Vinho e do Azeite \\
\hline Chaves & Sabores e Saberes de Chaves \\
\hline Freixo E. à Cinta & Quinzena das Amendoeiras em Flor; Festa das Sopas e Merendas \\
\hline Lamego & EXPODOURO; Festa do Vinho e Produtos Regionais. \\
\hline M. de Cavaleiros & $\begin{array}{l}\text { Feira da Caça e do Turismo; Rural Arcas - Feira dos Produtos da Terra; } \\
\text { Entrudo Chocaleiro de Podence; Feira do Azeite e da Caça de Chacim. }\end{array}$ \\
\hline Mesão Frio & Feira de Santo André. \\
\hline Miranda do Douro & Festival de Sabores Mirandeses; Famidouro; Feira Arribas em Flor (Sendim) \\
\hline Mirandela & Festival de Sabores do Azeite Novo; Feira da Alheira \\
\hline Mogadouro & Amendoeiras em Flor; Produtos da Terra de Bemposta; Feira dos Gorazes. \\
\hline Moimenta da Beira & Festa da Maça. \\
\hline Montalegre & Feira do Fumeiro e Presunto do Barroso; Feira da Vitela do Barroso. \\
\hline Murça & Feira do Azeite, do Vinho e Produtos Regionais. \\
\hline Peso da Régua & Festa do Vinho e Produtos Regionais; Festa das Vindimas do Douro. \\
\hline Penedono & Feira Medieval de Penedono. \\
\hline Ribeira de Pena & Feira do Linho, Festa do Maronês e Sabores das Terras de Pena. \\
\hline Sabrosa & Feira Medieval. \\
\hline S. João Pesqueira & Festa dos Saberes e Sabores do Douro; VINDOURO. \\
\hline Sernancelhe & Festa da Castanha. \\
\hline S. Marta Penaguião & Semana Cultural de Santa Marta de Penaguião. \\
\hline Tabuaço & Encontro Saberes e Odores (Granja do Tédo); Feira da Vindima de Barcos \\
\hline Tarouca & Feira das Profissóes. \\
\hline Torre de Moncorvo & $\begin{array}{l}\text { Amendoeiras em Flor; Feira dos Produtos da Terra; Feira da Cereja; Mostra } \\
\text { de Vinhos, Amêndoa e Stocks. }\end{array}$ \\
\hline Valpaços & $\begin{array}{l}\text { Feira do Fumeiro (São Joáo da Corveira); Feira do Folar; Salão de vinho de } \\
\text { Trás-os-Montes; Feira da Castanha em Carrazedo de Montenegro. }\end{array}$ \\
\hline Vila Flor & $\begin{array}{l}\text { Feira Gastronomia, Artesanato e Produtos Regionais (Freixiel); Feira } \\
\text { Produtos e Sabores. }\end{array}$ \\
\hline Vila Nova Foz Côa & Quinzena das Amendoeiras em Flor (inclui Feira Franca da Amendoeira). \\
\hline Vila P. de Aguiar & $\begin{array}{l}\text { Feiro do Granito; Feira do Mel e do Artesanato (Pedras Salgadas); Feira da } \\
\text { Castanha, Cabrito, Carne Maronesa e Cogumelos; Feira das Cebolas. }\end{array}$ \\
\hline Vila Real & Festa do Vinho e Produtos Regionais; Feira de Artesanato e Gastronomia. \\
\hline Vimioso & Festival Sons e Ruralidades; Feira das Artes, Ofícios e Sabores. \\
\hline Vinhais & $\begin{array}{l}\text { Feira do Fumeiro; Feira de Produtos da Terra, Mostra de Artesanato e } \\
\text { Encontro Venatório de Agrocháo; Feira da Castanha. }\end{array}$ \\
\hline
\end{tabular}


êxito, pois o cliente que fica satisfeito repete a compra, torna-se habitual na feira e na terra. Manter ou melhorar a qualidade é algo que os comerciantes locais sabem que é essencial para se continuar a realizar a feira, dado que o público é cada vez mais exigente, e ainda bem, porque assim se vai ao encontro do que é fundamental: melhorar, para acompanhar o progresso. E aproveitando a exploração dos recursos endógenos tem resultado desenvolvimento, que atenua a perda de populaçáo, decorrente do êxodo rural, e o envelhecimento, causado pela constante (e)migração dos jovens de sucessivas geraçóes.

A organização é assumida pelos municípios, mas têm colaboração das gentes e actores locais e do associativismo não económico, realizando-se em infra-estruturas existentes nos municípios, como pavilhóes desportivos, parques de exposiçóes, sendo, por vezes, criadas estruturas amovíveis cobertas. A face mais visível é o mercado de bens do sector primário e seus transformados, vendendo-se parte de algumas produçóes anuais. Mas porque razão, os visitantes vêm de táo longe? Na última Feira da Caça e do Turismo, o presidente da Câmara, acabou por dar a resposta ou parte da resposta: os produtos são bons e as pessoas ficam satisfeitas.

Quanto ao direito a expor nas feiras temáticas, talvez para compensar os feirantes, pela fixação de limites de preços em alguns certames e devido ao facto da produção e venda ser sazonal, o comum, ou prática em alguns eventos, é a existência de um convite, podendo, por exemplo, os participantes da feira do Fumeiro de Vinhais reservar o seu espaço para o ano seguinte. Mas para estar presente neste tipo de eventos também é necessário, em alguns casos, como na feira do Fumeiro de Montalegre, cumprir as regras e requisitos estabelecidos. $\mathrm{O}$ aumento do volume de feiras, contribuiu para o aumento do número de produtores e da produção do fumeiro cada vez mais exportado a nível interregional e internacional, atraindo turistas de todo o país, milhares de espanhóis, mas também turistas do Centro e Norte da Europa Relativamente ao número de visitantes do conjunto das feiras temáticas, muito facilmente é possível que duplique o da população da região, superior a 450.000 pessoas, a avaliar pela amostra (Quadro 2). As feiras do fumeiro têm organizaçóes muito profissionalizadas: em Vinhais, Montalegre e Boticas, a estratégia de comunicação é concebida e monitorizada por agências de publicidade, atingindo-se de forma continuada entre 50 a 100 mil visitantes por feira.

\begin{tabular}{|c|c|c|c|c|}
\hline Feira & Visitantes* & Expositores & $\begin{array}{l}\text { Produto** } \\
\text { (mil euros) }\end{array}$ & $\begin{array}{l}\text { Investimento (mi } \\
\text { euros) }\end{array}$ \\
\hline $\begin{array}{l}\text { Fumeiro de } \\
\text { Montalegre }\end{array}$ & 65.000 & $>100$ & $>1000$ & 100 \\
\hline Porco de Boticas & 35.000 & $\begin{array}{c}60 \text { (outros produtos: } \\
30 \text { ) }\end{array}$ & 300 & - \\
\hline Fumeiro de Vinhais & 80.000 & $120-130$ de fumeiro & $>1000$ & - \\
\hline Folar de Valpaços & 70.000 & $75(65$, em 2006) & 1000 & 75 (90, em 2006) \\
\hline Mel e Carne de Boticas & 20.000 & 40 & 150 & - \\
\hline $\begin{array}{l}\text { Gorazes do } \\
\text { Mogadouro }\end{array}$ & 30.000 & $>100$ & - & - \\
\hline
\end{tabular}


É importante salientar as externalidades criadas por estes eventos que se revertem em receitas indirectas, não só criando riqueza, como oportunidades de negócios. Em Montalegre, estimam-se cerca de 5 milhóes de euros, não apenas receitas provenientes directamente da feira, pois também a hotelaria e a restauração ficam totalmente ocupados, levando os turistas a consumir, tendo sido referido pelos autarcas locais que em pouco tempo abriram no concelho cerca de vinte salas de restauração, com melhores condiçóes de espaço e decoração. Da mesma forma, em Vinhais, e de acordo com o presidente da Câmara, só as actividades ligadas ao fumeiro criam receitas avaliadas em meio milhão de euros, aumentando sequencialmente, ao longo do ano, o turismo gastronómico e do património. A pecuária associada ao aumento no número de porcas reprodutoras (de 111 porcas reprodutoras inscritas em 1995 para 634 porcas em 2001) e o aumento na quantidade de produção do fumeiro estão associados à subsistência das populaçóes.

Estas iniciativas procuram também uma valorização dos produtos biológicos. A cereja e oleaginosas, a azeitona e o azeite, a vinha e o vinho, as carnes e os leites, o mel e os cosméticos, etc, produzidos em modo biológico, têm vindo a assumir um papel crescente, embora parte dos produtores ainda vendam os seus produtos nos circuitos da agricultura intensiva. Verifica-se também um crescente aumento dos expositores denominados "gourmet”. Os visitantes forasteiros reconhecem e apreciam as identidades territoriais exibidas, contribuindo para a divulgação e valorização, permitindo aos produtores locais o escoamento dos produtos, gerando volumosas receitas directas. Além dessas, as feiras criam externalidades (receitas entradas nos estabelecimentos locais, acordos comerciais, desejo de voltar aos territórios) e estimulam as actividades agrárias, algumas indústrias, o turismo, o comércio e os transportes (excursóes). Ao incluírem debates, as feiras têm promovido a troca de saberes, muitas vezes entre o urbano/metropolitano e o rural, sendo também instrumentos de promoção do desenvolvimento sustentável.

\section{A FEIRA DO FUMEIRO DE VINHAIS E A FEIRA DA CAÇA E DO TURISMO DE MACEDO DE CAVALEIROS}

Centrado nas feiras de produtos locais de Trás-os-Montes e Alto Douro, foram realizados inquéritos aos visitantes e expositores de 2 destas feiras: Feira do Fumeiro de Vinhais e Feira da Caça e Turismo de Macedo de Cavaleiros. Através dos inquéritos aos visitantes e expositores procura-se avaliar o significado destes eventos na dinamização das actividades locais e na manutenção da população, avaliar a sua visibilidade nos territórios urbanos e a capacidade de atracção de visitantes de fora da região/país, bem como avaliar os seus impactos. Antes de proceder à apresentação dos resultados apresentamos uma descrição de cada um dos eventos.

A feira do Fumeiro de Vinhais realiza-se desde 1981, no segundo fim-de-semana de Fevereiro, com organização da Câmara Municipal e da Associação Nacional de Criadores de Suínos de Raça Bísara. Normalmente tem a duração de quatro dias, com um vasto programa de actividades, exposiçóes, concursos e espectáculos. Mais que uma feira é já a maior festividade do concelho. No último certame, cerca de 80.000 pessoas de todo o país e estrangeiro visitaram a feira (o número de visitantes foi semelhante ao ano anterior, e não superior, devido à queda de neve ocorrida nesse fim-de-semana). $\mathrm{Na}$ feira estiveram presentes 130 produtores de fumeiro (20 cozinhas regionais, 5 indústrias e produtores 
individuais), procurando apresentar um fumeiro de qualidade, confeccionado a partir de porcos autóctones de raça Bísara da região, tendo sido vendidos 550 porcos, estimando-se num volume de negócios de venda de fumeiro a rondar os 550 mil euros, tendo-se escoado a generalidade do fumeiro. O escoamento do fumeiro de alguns expositores faz-se sentir logo no início da feira devido às encomendas do ano anterior e à forte procura no primeiro dia, sendo mais procurados os expositores já conhecidos. Os números, na óptica do edil local, comprovam a importância da feira, que além de ser conhecida, marca a agenda de um elevado número de espanhóis e visitantes de fora, que descobriram Vinhais e agora vêm em grande número.

Para além do fumeiro, os expositores também comercializam outros produtos locais (de pão a produtos hortícolas). Também nas tasquinhas no recinto da feira confeccionamse pratos de fumeiro, tal como nos restaurantes oficiais, bem como outros pratos típicos. Do programa constou ainda o artesanato, com privilégio a artesãos com trabalhos ao vivo e que residem no concelho, tendo dezenas de artesãos estado presentes mas, segundo o edil local, outros tantos aguardam para estar presentes, tal como acontece nos vários sectores presentes, tendo a última edição apresentado a maior procura por parte de expositores. $\mathrm{O}$ espaço Gourmet foi uma novidade da última edição com 40 expositores, sendo considerado uma aposta ganha, com os presentes a garantir presença para o próximo ano. A Eng. Carla Alves da organização considera que com o título de Vinhais Capital do Fumeiro, o concelho aumenta anualmente o volume de visitantes, de fumeiro vendido e de negócios em geral, melhorando gradualmente o certame, com maior profissionalismo e rigor no controlo e certificação de todo o fumeiro, garantindo aos consumidores a genuidade e autenticidade destes produtos.

A Feira da Caça e do Turismo de Macedo de Cavaleiros realizou-se no último fim-desemana de Janeiro, organizada pela Câmara Municipal e pela Federação das Associaçóes da $1^{\text {a }}$ Região Cinegética. O certame foi inaugurado pelo Secretário de Estado do Turismo que salientou a importância destas iniciativas para o interior, fundamental para valorizar os produtos locais e promover o turismo. A organização pretende converter o concelho, não apenas numa referência na área cinegética, mas num destino turístico, onde sobressaia a paisagem e o património, aliados à qualidade dos produtos, da gastronomia e do saber receber das suas gentes. O Presidente da Federação de Caçadores da $1^{\text {a }}$ Regiáo Cinegética salientou que caça e turismo são duas actividades com grande peso e potencialidades na economia local e regional.

Para além de actividades de caça e lazer (montarias, Copa Ibérica de Caça com Falcôes, Raid Turístico, Prova de Santo Humberto, Prémio Galaico-Português, Troféu Ibérico de Tiro com Arco e Corrida de Galgos), no Parque Municipal de Exposiçóes, a feira tinha cerca de $6.000 \mathrm{~m} 2$ de área coberta, com produtos regionais e gastronómicos, diversas associaçóes culturais e organizaçóes locais a divulgarem os produtos e locais do concelho, operadores de turismo rural, artesãos, cooperativas agrícolas, produtores de vinho, queijo, doçarias, fumeiro e comerciantes de produtos para caça e pesca. Refira-se ainda a realizaçáo de um seminário sobre "Apoios Financeiros no Sector da Caça e do Turismo" e a apresentação da antologia "Páginas de Caça na Literatura de Trás-os-Montes", de Pires Cabral.

Durante os quatro dias do evento mais de 20 mil pessoas passaram pelo recinto da Feira, entre os quais se contaram muitos caçadores e participantes nas actividades. Os visitantes lotaram a oferta hoteleira do concelho, tendo alguns ficado instalados em municípios vizinhos. O presidente da Câmara Municipal, no discurso de abertura, referiu que 
juntar a caça e o turismo é uma oportunidade para valorizar os dois sectores, aproveitando o que têm em comum, valorizaçáo que tem de ser sustentável, sendo importante que o turismo e a caça permitam gerar rendimentos às famílias. Foi ainda salientado que a feira é necessária para mostrar a riqueza e identidade cultural, sendo essencial realizar ao longo de todo o ano um leque de actividades que permitam atrair pessoas, aumentando as alternativas e opçóes para quem visita a regiáo, tornando-a num destino turístico ao longo de todo o ano, fortalecendo a economia, criando riqueza e empregos.

\subsection{Alguns números dos visitantes das feiras}

No inquérito aos visitantes foram abordados os seguintes aspectos: idade; escolaridade; profissão; freguesia e concelho de residência; número de feiras de produtos locais visitadas durante o ano; concelhos onde normalmente visita estas feiras; porque visita este tipo de feiras; que importância atribui a estes eventos e de que forma poderão ser importantes para a região. No conjunto das duas feiras foram realizados 428 inquéritos aos visitantes. No Quadro 3 apresentam-se alguns dados resultantes dos inquéritos realizados.

Quadro 3-Dados dos inquéritos realizados aos visitantes das feiras

\begin{tabular}{|c|c|}
\hline Questão & Dados relevantes \\
\hline Idade & $\begin{array}{l}\text { A média de idades dos visitantes varia entre } 44 \text { anos (Feira da Caça e } \\
\text { Turismo) e } 46 \text { anos (Feira do Fumeiro), evidenciando-se o grupo etário } \\
\text { entre } 40 \text { e } 64 \text { anos ( } 52,8 \% \text { dos visitantes). }\end{array}$ \\
\hline Escolaridade & $\begin{array}{l}\text { Evidencia-se o peso dos visitantes com ensino superior (33,6\%), contudo } \\
\text { existe uma diferença entre as } 2 \text { feiras: } 38,8 \% \text { na Feira do Fumeiro e } \\
28,8 \% \text { na Feira da Caça e Turismo. }\end{array}$ \\
\hline Profissão & $\begin{array}{l}\text { Os comerciantes/empresários representam } 16,6 \% \text { dos visitantes das duas } \\
\text { feiras ( } 17,8 \% \text { na Feira da Caça e Turismo e } 15,3 \% \text { na Feira do Fumeiro), } \\
\text { realçando-se ainda o peso dos reformados na Feira do Fumeiro (12,9\%). }\end{array}$ \\
\hline Residência & $\begin{array}{l}\text { A maioria dos visitantes vem de fora da regiáo }(34,8 \%) \text {, valor mais elevado } \\
\text { na Feira do Fumeiro }(40,7 \%) \text {, enquanto } 3,3 \% \text { dos visitantes sáo } \\
\text { estrangeiros. Os visitantes do concelho representam } 32,9 \% \text { ( } 40,2 \% \text { na } \\
\text { Feira da Caça e Turismo e } 25,4 \% \text { na Feira do Fumeiro), enquanto } 29 \% \\
\text { sáo provenientes de outros concelhos transmontanos }(27,4 \% \text { e } 30,6 \% \text {, } \\
\text { respectivamente). }\end{array}$ \\
\hline $\begin{array}{l}\text { Quantas feiras } \\
\text { visita }\end{array}$ & $\begin{array}{l}\text { A maioria dos visitantes }(61,7 \%) \text { visita entre } 2 \text { a } 4 \text { feiras por ano }(58,4 \% \\
\text { dos visitantes da Feira da Caça e Turismo e } 65,1 \% \text { da Feira do Fumeiro). }\end{array}$ \\
\hline $\begin{array}{l}\text { Concelhos visita } \\
\text { estas feiras }\end{array}$ & $\begin{array}{l}50 \% \text { dos visitantes apenas frequenta feiras realizadas na regiáo ( } 47,5 \% \text { na } \\
\text { Feira da Caça e Turismo e 52,6\% dos visitantes da Feira do Fumeiro). }\end{array}$ \\
\hline $\begin{array}{l}\text { Porque visita } \\
\text { este tipo de } \\
\quad \text { feiras }\end{array}$ & $\begin{array}{l}60,5 \% \text { referem os produtos locais e tradicionais e o artesanato como } \\
\text { motivo ( } 36,5 \% \text { na Feira da Caça e Turismo e } 85,6 \% \text { na Feira do } \\
\text { Fumeiro); } 50,2 \% \text { o gosto, interesse, convívio e a curiosidade }(57,1 \% \text { e } \\
43,1 \% \text {, respectivamente); } 44,9 \% \text { o turismo, a caça e provas de caça ou } \\
\text { turismo, lazer e passeio ( } 40,2 \% \text { e } 49,8 \% \text {, respectivamente); } 19,4 \% \\
\text { referem os familiares e amigos, a identificaçáo com local e região e a } \\
\text { cultura tradicional ( } 13,7 \% \text { e } 25,4 \% \text {, respectivamente). }\end{array}$ \\
\hline
\end{tabular}


$61,9 \%$ referem a preservaçáo, divulgaçáo e valorizaçáo produtos locais e mostra de tradiçóes e cultura local $(59,8 \%$ na Feira da Caça e Turismo e 64,1\% na Feira do Fumeiro); 48,8\% a divulgação, dinamização e desenvolvimento do concelho e da região ( $42 \%$ e $56 \%$, respectivamente); $35 \%$ a atracção de visitantes e promoção e valorização do turismo $(36,1 \%$ e $34 \%$, respectivamente); $11 \%$ referem o convívio e as novidades apresentadas $(15,5 \%$ e $6,2 \%$, respectivamente).

\subsection{Alguns números dos expositores}

No inquérito aos expositores foram abordados os seguintes aspectos: idade; escolaridade; profissão; concelho de residência; em quantas feiras de produtos locais expóe; em que concelhos expóe; produtos expostos; \% de vendas em feiras; importância no rendimento anual; porque visita este tipo de feiras; mais-valias de venda em feiras; que importância atribui a estes eventos. Nas duas feiras foram realizados 130 inquéritos aos expositores. No Quadro 4 apresentam-se alguns dados dos inquéritos realizados aos expositores.

Quadro 4-Dados dos inquéritos realizados aos expositores das feiras

\begin{tabular}{|c|c|}
\hline Questão & Valores relevantes \\
\hline Idade & $\begin{array}{l}\text { Evidencia-se o grupo etário entre } 40 \text { e } 64 \text { anos ( } 49,2 \%) \text {, sendo } 42 \text { anos a } \\
\text { média de idades dos expositores da Feira da Caça e Turismo e } 49 \text { anos nos } \\
\text { expositores da Feira do Fumeiro. }\end{array}$ \\
\hline Escolaridade & $\begin{array}{l}39,2 \% \text { tem escolaridade até ao } 1^{\circ} \text { ciclo }(39,2 \%) \text {, sendo } 14,3 \% \text { na Feira da } \\
\text { Caça e Turismo e } 46,1 \% \text { dos expositores da Feira do Fumeiro. }\end{array}$ \\
\hline Profissão & $\begin{array}{l}27,7 \% \text { tem como profissáo agricultor ou doméstica; } 23,1 \% \text { dos exposi- } \\
\text { tores tem como profissão artesão / marceneiro / escultor; } 16,9 \% \text { tem por } \\
\text { profissáo comerciante / empresário. }\end{array}$ \\
\hline Residência & $\begin{array}{l}50,8 \% \text { dos expositores residem no concelho, sendo } 22,3 \% \text { exteriores à } \\
\text { região. }\end{array}$ \\
\hline $\begin{array}{l}\text { Quantas feiras } \\
\text { expốe }\end{array}$ & $\begin{array}{l}33,8 \% \text { visita } 5 \text { ou mais eventos do género por ano; } 27,7 \% \text { frequenta } \\
\text { apenas } 1 \text { feira por ano e } 26,2 \% \text { entre } 2 \text { e } 4 \text { feiras. }\end{array}$ \\
\hline $\begin{array}{l}\text { Em que em } \\
\text { concelhos expóe }\end{array}$ & $\begin{array}{l}50 \% \text { expóe apenas no concelho; } 33,8 \% \text { em feiras de todo o país; } 9,2 \% \text { em } \\
\text { feiras da região de Trás-os-Montes e 6,9\% também no estrangeiro. }\end{array}$ \\
\hline $\begin{array}{l}\text { Que produtos } \\
\text { expóe }\end{array}$ & $\begin{array}{l}48,5 \% \text { expóe produtos regionais e de gourmet (fumeiro, vinho, azeite, } \\
\text { licor), enquanto } 37,7 \% \text { expóem artesanato e } 10 \% \text { apenas pretendem a di- } \\
\text { vulgação. }\end{array}$ \\
\hline $\begin{array}{l}\% \text { de vendas e } \\
\text { rendimentos em } \\
\quad \text { feiras }\end{array}$ & $\begin{array}{l}\text { As vendas nas feiras representam entre } 50-74 \% \text { das vendas para } 26,9 \% \\
\text { dos expositores; Para } 55,4 \% \text { dos expositores a venda em feiras de produtos } \\
\text { locais representa menos de } 25 \% \text { do seu rendimento anual. }\end{array}$ \\
\hline $\begin{array}{l}\text { Porque } \\
\text { frequenta este } \\
\text { tipo de feiras }\end{array}$ & $\begin{array}{l}46,9 \% \text { referem a necessidade de vender os produtos e obter rendimentos; } \\
45,4 \% \text { a divulgação, promoção e obtenção de contactos; } 30 \% \text { o gosto, } \\
\text { lazer e convívio; } 22,3 \% \text { a tradição e ser feira do concelho. }\end{array}$ \\
\hline $\begin{array}{l}\text { Já teve mais- } \\
\text { valias com a } \\
\text { presença nas } \\
\text { feiras }\end{array}$ & $\begin{array}{l}71,6 \% \text { dos expositores considera que já teve mais valias para a sua acti- } \\
\text { vidade resultantes da presença nestas feiras, para além das vendas efectua- } \\
\text { das durante a feira, enquanto } 12,7 \% \text { refere que não teve mais-valias e } \\
17,7 \% \text { não dos expositores inquiridos não respondeu. }\end{array}$ \\
\hline
\end{tabular}




\begin{tabular}{|c|c|}
\hline $\begin{array}{l}\text { Que } \\
\text { importância } \\
\text { atribui a estas } \\
\text { feiras }\end{array}$ & $\begin{array}{l}66,2 \% \text { referem a preservação, divulgação, valorização e venda dos produ- } \\
\text { tos locais (obtençáo de rendimento); } 63,1 \% \text { a divulgaçáo, dinamizaçáo e } \\
\text { desenvolvimento do concelho e da região; } 30,8 \% \text { a atracção de visitantes e } \\
\text { a promoçáo e valorização do turismo. }\end{array}$ \\
\hline
\end{tabular}

\section{CONCLUSÃo}

As feiras temáticas, numa região como esta, são instrumentos através dos quais a identidade se revela um recurso para o desenvolvimento dos territórios, recurso cada vez mais reconhecido, atractivo e, por isso, contribui para despertar o interesse das populaçóes urbanas de outras regióes por este território de baixa densidade do interior.

Podemos considerar que contribuem para despertar o interesse das populaçóes urbanas de outras regiōes por esta região, contribuindo para a alteração das dinâmicas dos territórios, aumentando a atractividade externa e alterando-se o relacionamento urbano - rural. Por fim, refira-se que estas feiras são um instrumento de revitalização/modernização da economia rural, contribuindo para suster o processo de esvaziamento demográfico.

\section{REFERÊNCIAS BIBLIOGRÁFICAS}

Baptista, F. O. 2009, "Territórios de baixa densidade: olhares prospectivos", in Os territórios de baixa densidade em tempos de Mudança, Eds O. Baptista, R. Jacinto e T. Mendes, Câmara Municipal de Proença a Nova, Centro de Ciência Viva da Floresta, pp.7-8.

Cavaco, C. 2009, "Os espaços rurais como espaços de vida: mobilidades residenciais e novas formas de habitar", in Os territórios de baixa densidade em tempos de Mudança, Eds O. Baptista, R. Jacinto e T. Mendes, Câmara Municipal de Proença a Nova, Centro de Ciência Viva da Floresta, pp.39-72.

Cristóvão, A. 1998, "Em Busca da Esmeralda Perdida? Reflexão sobre o Mundo Rural Português". Seminário Mundo Rural e Agricultura, Vila Real.

Ferrão, J. 2003, "Dinâmicas Territoriais e Trajectórias de Desenvolvimento: Portugal 1991-2001", Revista de Estudos Demográficos, INE, n. 34, pp. 17-25.

Figueiredo, E. 1994, "O Espaço Rural em Questáo - Contributo para uma Reflexão em Torno do Conceito de Ruralidade”, Rurália, n. 3, pp. 23-31.

Marques, H. 2008, "Porquê (e razôes para) a mitificação do campo", VII Colóquio Ibérico Estudos Rurais: Cultura, Inovação e Território, Coimbra.

Marques, T. S. 2004, Portugal na Transição do Século. Retratos e dinâmicas territoriais, Afrontamento, Porto. 